\title{
Proceso de Producción y Exportación que realiza la empresa de tabacos A.J. FERNANDEZ en el periodo $2013^{1}$
}

\author{
Carmen María Castillo Benavidez ${ }^{2}$ \\ Yasser Eduardo Rivera Soto ${ }^{3}$ \\ Beverly Castillo Herrera ${ }^{4}$
}

\section{RESUMEN}

En el presente estudio investigativo se realizó una evaluación sobre el proceso de producción y exportación que realiza la Empresa de Tabacos A.J. FERNANDEZ en el segundo semestre 2013. Esta investigación es cualitativa, aborda a profundidad el proceso de producción y exportación realizada por dicha empresa. Las principales recomendaciones para la empresa procesadora de tabacos se enfocan en el seguimiento al proceso de administración en las actividades de producción y exportación, así como velar por el cumplimiento de las Buenas Prácticas de Manufactura (BPM).

Palabras claves: Administración, producción exportación.

Recibido: 15 de diciembre de 2014

Aceptado: 02 de octubre de 2015

1 Este artículo se basa en la investigación titulada Proceso de Producción y exportación que realiza la empresa de tabacos AJFERNANDEZ en el segundo semestre 2013. Para optar al título de Licenciatura en Administración de Empresas por la UNAN-Managua, FAREM-Estelí.

2 UNAN-Managua, FAREM-Estelí. Correo electrónico:Carmen.castillo1991@yahoo.es

3 UNAN-Managua, FAREM-Estelí. Correo electrónico:Yassert92@gmail.com

4 Master en Ciencias Sociales por la Universidad de Guadalajara, estudiante del Doctorado en Ciencias Sociales de la Universidad del Zulia. Docente titular de la UNAN-Managua, FAREM-Estelí. Correo electrónico:

beverly.castillo@yahoo.com 


\section{Production and exporting process done by the tobacco company in the A.J. FERNANDEZ during the year 2013}

\section{SUMARY}

In this research study an evaluation of the process of production and exports done by the tobacco company in A.J. FERNANDEZ in the second half of 2013. This research is qualitative approaches in depth the process of production and exports by that company. The main recommendations for the tobacco processing company focusing on monitoring the management process in the production and export activities, as well as ensuring compliance with Good Manufacturing Practices (GMP).

Keywords: Administration, exporting, production 


\section{INTRODUCCIÓN}

La ciudad de Estelí, a nivel nacional e internacional, se ha distinguido como productora de tabaco, A partir de los años noventa se incrementó la instalación de fábricas de tabaco en locales inadecuados para la producción y la seguridad laboral pero que después fueron mejorando sus condiciones.

Una de las fábricas productoras de tabaco que se han establecido en la ciudad de Estelí es la tabacalera A J Fernández fue fundada en el año 2008. Actualmente A.J. FERNANDEZ con una infraestructura adecuada donde laboran 650 trabajadores con un nivel de producción de 45,000 puros diarios y exporta a Estados Unidos, Suecia entre otros.

A.J. FERNANDEZ Cigars es una empresa de bienes se dedica a la producción y comercialización de cigarros puros de diferentes ligas, tamaños y estilos destinados a la exportación. Las operaciones de esta compañía son controladas y supervisadas por su propietario, el señor Abdel Fernández, quien cuida cada uno de los detalles utilizados en la técnica en este rubro y heredada de la familia Fernández.

Es una empresa privada que opera como empresa de zona franca fue aprobada por la comisión nacional de zonas francas para operar bajo este régimen fiscal especial el 21 de enero del 2009.

Desde esa fecha a la actualidad han alcanzado un notable crecimiento tanto en generación de empleo como en exportaciones, lo que les ha permitido desarrollar un nuevo proyecto de inversión que consiste en la construcción de un edificio propio.

\section{MATERIALES Y MÉTODOS}

La presente investigación es aplicada ya que estudia y analiza un problema real para plantear propuestas que mejoren el funcionamiento de la empresa procesadora de tabacos A.J. FERNANDEZ. Así mismo esta investigación es tipo cualitativa porque aborda a profundidad la problemática de administración, producción y exportación.

Este es una investigación con muestra No Probabilística, de tipo causal porque no todo el universo tiene La probabilidad de ser seleccionado. Dentro de los criterios de selección de la muestra están: 1) Disposición de tiempo los trabajadores para colaborar con la investigación; 2) Personas involucradas en el proceso de Producción Y exportación de tabacos 3) Experiencia de 2 a más años en el área productiva.

Para el cumplimiento de los objetivos que se plantean en esta investigación se utilizaron tres técnicas de recolección de datos: la investigación documental, la entrevista semi-estructurada y la guía de observación.

\section{RESULTADOS Y DISCUSIÓN}

Nicaragua tiene las mejores tierras para la producción de tabaco y la demanda de este producto es a nivel mundial, actualmente hay un incremento significativo de las áreas de siembra y por lo tanto hay contratación de fuerza laboral cada vez más especializada, tanto para el proceso de producción como para la administración de los recursos de las empresas. El personal tiene altas oportunidades de empleo.

Una de las principales actividades en el municipio de Estelí es el cultivo y procesamiento de tabaco convirtiéndose en la principal fuente de empleo y contribuye al desarrollo económico y social del municipio.

En el municipio algunos procesos tienen encadenamientos industriales dada que la materia prima procesada pasa por distintas etapas ante de convertirse en producto final. 
En la actualidad A.J. FERNANDEZ cuenta con diferentes áreas en dicha empresa destinadas para la elaboración de puros y personal capacitado que laboran en ellas en las cual citamos a continuación: Tabla \#1

\begin{tabular}{lr}
\hline \multicolumn{1}{c}{ Áreas } & No de empleados $^{\circ}$ \\
\hline Gerente general & 1 \\
Gerente administrativo & 1 \\
Gerente de contabilidad & 1 \\
Auxiliares contables & 6 \\
Importaciones y exportaciones & 1 \\
Gerente de RRHH & 1 \\
Auxiliares de RRHH & 2 \\
Higiene y Seguridad & 1 \\
Gerente de Producción & 1 \\
Pilones & 63 \\
Bodegas de pacas & 1 \\
Majaderos & 2 \\
Acondicionamiento y & 4 \\
humidificación & \\
Secado de tripa & 5 \\
Máquina de paca & 3 \\
Despalillo & 109 \\
Área de capa & 80 \\
Entrega de MP & 3 \\
Producción de puros & 260 \\
Control y calidad & 12 \\
Empaque & 50 \\
Bodega & 3 \\
\hline &
\end{tabular}

Misión, Visión, Valores y Estructura Organizativa

\section{Misión}

Producir puros de la mejor calidad utilizando tabacos de Nicaragua, llenando las expectativas de sus consumidores y haciéndolos asequibles de manera efectiva; siendo así una empresa socialmente responsable, líder en calidad, productividad e innovación Aplicando estrategias y métodos con un enfoque de conservación y usos sustentables de los recursos naturales.

\section{Visión}

Satisfacer las necesidades de los clientes a través de marcas internacionales y de alto valor añadido. Capacitar a nuestros trabajadores continuamente, y brindarles las condiciones laborales ideales para lograr el máximo desarrollo de su potencial profesional y humano. Aportando al desarrollo del país, mediante la creación de fuentes de trabajo, y la generación de divisas por medio de exportaciones a diversos mercados del mundo.

Valores

- Honestidad

- Calidad de servicio

- Esfuerzo

- Amor al trabajo

- Innovación

\section{Proceso administrativo en función de la producción:} Grafico \#1

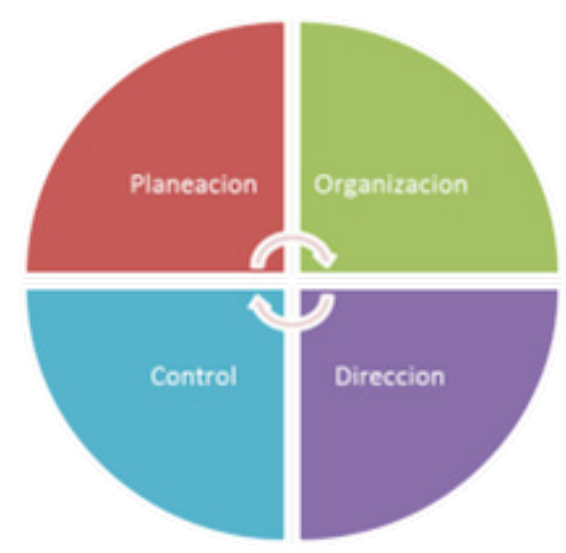

\section{Planeación}

Esta etapa abarca la definición de las metas de la organización, el establecimiento de una estrategia general para alcanzar esas metas y el desarrollo de una jerarquía minuciosa de los planes para integrar y coordinar las actividades; establecer metas sirve para no perder de vista el trabajo que se hará y para que los miembros de la organización fijen su atención en las cosas más importantes. 


\section{Organización}

Ejecutará, como estarán agrupadas, quién depende de quién, y dónde serán tomadas las decisiones. Esta etapa incluye determinar que tareas se llevarán a cabo, cómo serán realizadas, quién las organización es la distribución y disposición de los recursos organizacionales para alcanzar objetivos estratégicos. Esa distribución se refleja en la división del trabajo en unidades organizacionales, definición de líneas formales de autoridad y adopción de mecanismos para coordinar las diversas tareas organizacionales.

\section{Dirección}

Es la etapa encargada de motivar a los empleados, orientar las actividades de otros, elegir el canal más eficaz de comunicación, y resolver los conflictos entre los empleados. Esta es la función administrativa que se refiere a la relación interpersonal del administrador con su subordinado. Para que la planeación y la organización puedan ser eficaces, se deben complementar con la orientación y el apoyo de las personas a través de comunicación, liderazgo y motivación adecuados. Para dirigir a las personas, el administrador debe saber comunicar, liderar y motivar.

\section{Control}

Una vez que se han establecido las metas, se han formulado los planes, se ha definido el orden de la estructura y se ha contratado, capacitado y motivado al personal, se establece a cargo un administrador que se encargue de que las cosas marchen como es debido y que vigile el desempeño de los empleados de la organización. Se ve comprometido a comparar el desempeño real con las metas establecidas con anterioridad, y en el supuesto de que se lleguen a presentar desviaciones significativas, será el administrador el responsable de volver a encaminar a la organización por el camino correcto, a grandes rasgos, cuando se habla de la etapa de control, se hace referencia al método de vigilar, comparar y corregir. La finalidad del control es garantizar que los resultados de lo planeado, organizado y ejecutado se ajusten tanto como sea posible a los objetivos previamente establecidos. La esencia del control está en verificar si la actividad controlada está o no alcanzando los objetivos o resultados esperados. En este sentido, el control es básicamente un proceso que guía la actividad ejecutada hacia un fin previamente determinado. 


\section{Grafico \#2 Estructura organizativa de A.J. FERNANDEZ}






\section{Proceso de producción}

La empresa tabacalera A.J. FERNANDEZ ubicada en la ciudad de Estelí se dedica a la producción de puros de diferentes ligas tamaños y estilos destinados a la exportación esta empresa cuenta con tres diferentes áreas las cuales son área de pre-industria, área de producción Grafico \#3

\section{FLUJOGRAMA DEL PROCESO DE INDUSTRIA DE A.J. FERNANDEZ}

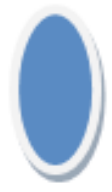<smiles></smiles>

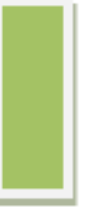

Recepción de materia prima
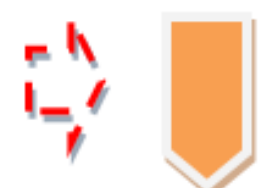

A rea de secado<smiles>C1CCC2CCC2C1</smiles>

Area de mojado
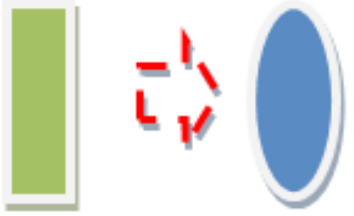<smiles>IC1CCCCC1</smiles>

Confección de

A rea de despalillo

$$
\text { puros }
$$

(moldeado y prensado)

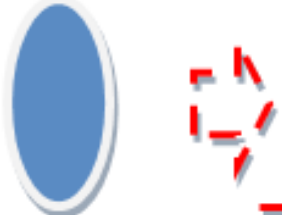

Controly calidad
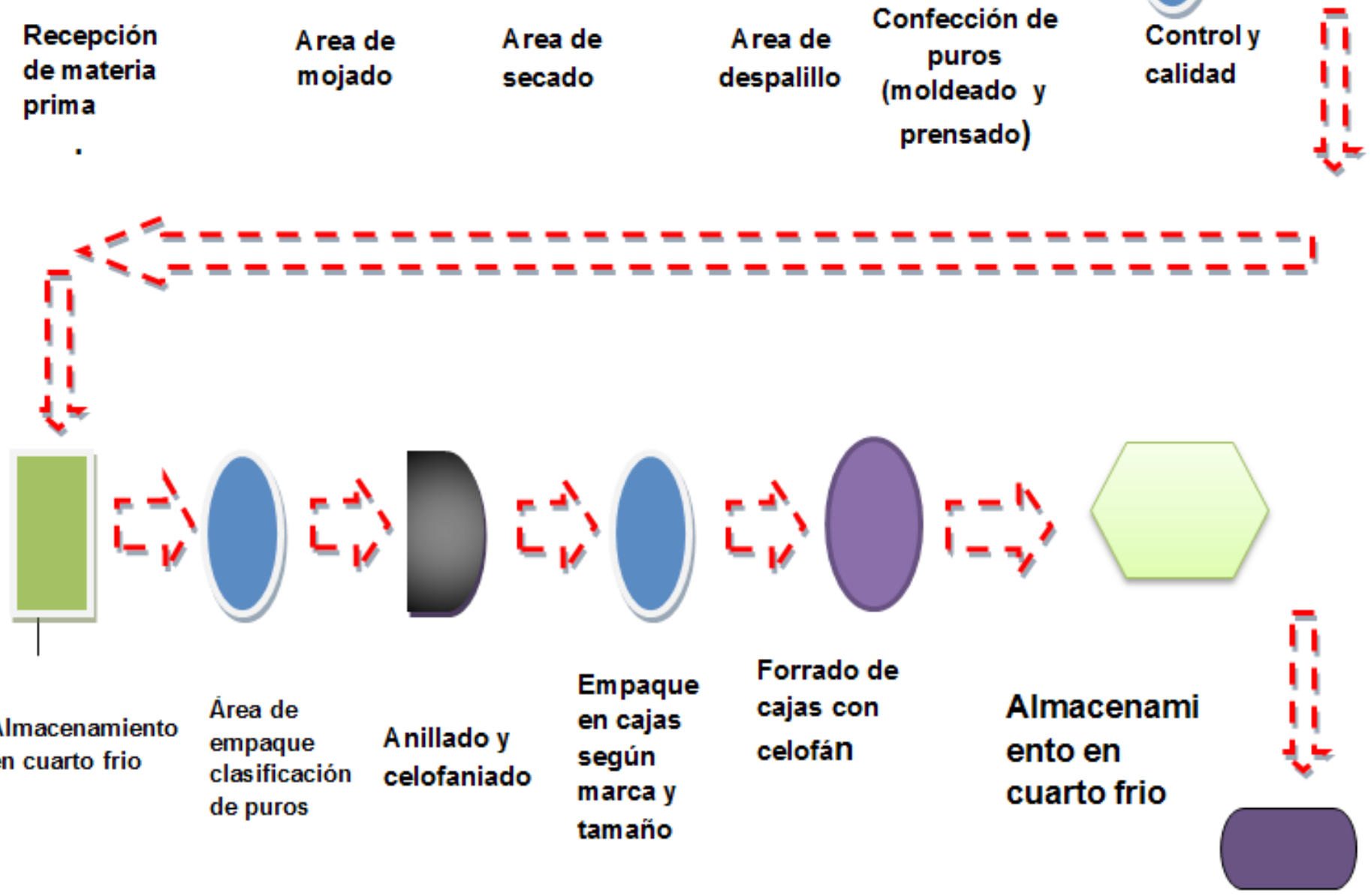

Producto final 
Paso 1. Recepcion de materia prima: existe un área específica en donde se almacena. El tabaco en pacas en espera para su debido proceso

Paso 2. Área de mojado: se procede abrir las pacas para mojar las hojas de tabaco y que se suavicen ya que vienen secas.

Paso 3. Área de secado: luego se procede a poner la capa colgada para la extracción de la humedad contenida en la hoja.

Paso 4. Despalillo: es donde se lleva la capa para la sustracción de la vena.

Paso5. Confección de puros: aquí se trae la hoja para que la realización de puros se le facilita al Bonchero para que el realice el puro. Luego se coloca en unas prensas para moldearlo y darle forma.

Paso 6. Control de calidad (rechazo y aprovechamiento): en esta área se evalúa si el puro producido cumple con los estándares de calidad exigidos por el cliente

Paso 7. Almacenamiento en cuarto frio: aquí se introduce a una determinada temperatura, esto se hace para eliminar del puro cualquier tipo de bacteria que tenga el puro.

Paso 8. Área de empaque y clasificación de puros: aquí se lleva el puro y es escogido, esta persona se encarga de clasificarle puro según su color y tamaño.

Paso 9. Anillado y selofaniado: luego se le lleva el puro ya clasificado a la empacadora y este lo anilla y lo introduce en una bolsa de celofán para conservar su sabor.

Paso 10. Empaque en cajas según su tamaño y marca: luego se introduce en cajas para su empaque final.
Paso 11. Forrado de cajas con papel celofán: ya rellenas las cajas de puros se procede a forrar las cajas con celofán para una mejor presentación y que el puro conserve su sabor.

\section{Políticas de calidad}

La empresa A.J. FERNANDEZ para las gestiones de calidad están ligadas con el MAGFOR quien tiene la obligación de asistir semanalmente a la empresa para la inspección de los productos terminados, esta institución se encarga de valorar si estos está en condiciones para su exportación o necesitan mejoras.

También se cuenta con la realización de pruebas fitosanitarias para los productos que su destino es la exportación, el MAGFOR en sus visitas hace una inspección sobre las áreas de trabajo, este identifica cuando se encuentran plagas y dependiendo de estas indica su tratamiento adecuado.

En sus políticas de calidad consiste en la previa supervisión de todo el proceso, como la tabacalera cuenta con sus propias fincas para la siembra de su tabaco es más fácil llevar un sistema de trazabilidad en cuanto a las siembras traslado a la empresa y realización del proceso de producción también sus políticas de calidad incluyen medidas preventivas y uso adecuado de uniforme para los trabajadores.

\section{Capacidades competitivas:}

Una de las capacidades competitivas que tiene la empresa de tabacos A.J. FERNANDEZ ya que los puros Nicaragüenses son tradicionalmente conocidos como productos de alta calidad tienen buena aceptación en el mercado internacional.

Además una ventaja para dicha empresa es su variedad de productos ofertados principalmente para personas con buen estatus social que deseen degustar los diferentes placeres del consumo del tabaco. 
Estándares de calidad exigidos para la satisfacción de los clientes:

- Calidad: capa pareja, sin manchas, buen olor, sabor agradable etc.

- Empaque: dependiendo de las marcas presentación y variedad sus clientes exigen que sea de calidad

- El precio: el precio del puro va a depender de acuerdo a la calidad la presentación y el tamaño del puro.

\section{Oferta y Demanda}

\section{Oferta}

La fábrica cuenta con una variedad de puros por capas marcas y medidas diferentes. La empresa cuenta con sus marcas propias.

EL San Lotano representa la leve a la oferta de cuerpo medio de la cartera de A.J. FERNANDEZ rodada con una envoltura sedosa cuidado con clima favorable del ecuador y relleno de semillas cubanas viso. Suave y cremoso el sabor del San Lotano es importante a pesar de la fuerza de perfil más suave del cigarro.

Cuenta con los mejores tabacos de diferentes regiones de Nicaragua captura los complejos sabores del exótico tabaco Nicaragüense regional, sino que también ofrece una suavidad muy aromatice que se ha convertido en el estándar de la marca AJ altamente productos codiciados.

Determinación de la demanda: La industria de los puros Nicaragüenses esta íntegramente orientada a la exportación por lo que su demanda es esencialmente externa. La demanda interna es prácticamente inexistente debido a la falta de costumbre de la población local para consumirlos a su elevado costo. La única forma de adquirir puros en el mercado local es a través del comercio destinado al turismo externo.

El vínculo demanda del mercado y producción según los tipos de mercados a los que se destina la producción de tabaco .el $100 \%$ de la producción tiene por destino la exportación, por lo cual la determinación de la demanda de tal mercado es el aspecto esencial de la actividad económica tabacalera.

\section{Fijación de precios}

Los precios dependen de la calidad del producto la cual es evaluada por el comercializador y por paneles independientes que renquean los productos en las revistas especializadas como cigarros aficionado esta evaluación de los expertos es un importante determinante de su precio en el mercado final.

Los puros nicaragüenses tradicionalmente conocidos como productos de alta calidad tienen buena aceptación en el mercado internacional. la calificación hecha de los puros de A.J. FERNANDEZ por la revista cigar aficionado en una escala de 0 a 100 , donde un producto con calificación inferior a 70 se considera de calidad deficiente . se considera que la mayoría de los productos evaluados por esta fuente más del $80 \%$ se ubican entre las calificaciones de 81 a 90 lo que confirma la afirmación anterior.

\section{Requisitos para exportar}

- Póliza revisada y autorizada por el CETREX.

- Factura comercial.

- Certificados

- Permisos especiales.

Cada trámite es diferente, porque puede venir la misma mercancía pero en diferente vía, esta puede ser terrestre, aérea o marítima:

- Guía aérea (este documento lo brinda la línea aérea por donde será enviado la mercancía

- Certificado de origen(donde fue hecha la mercancía)

- Permiso fitosanitario(lo brinda en MACFOR)

- DTI(declaración de mercancía para le transito aduanero internacional terrestre)

Ya que la empresa realiza los envíos por vía aérea por más seguridad de la mercancía ya que por vía marítima, 
la humedad puede causar daños en los puros se requiere un documento esencial para los envíos aéreos, es emitido por la compañía aérea o en sus defectos por un representante (agente de cargas).

\section{Líneas de estrategia para mejorar la exportación de A.J. FERNANDEZ}

Línea $\mathbf{N}^{\mathbf{0}}$ 1. Implementacion de un plan de higiene y seguridad laboral para los trabajadores que realizan las actividades de cultivo

Línea $\mathbf{N}^{0}$ 2. Analizar los mercados de exportación que sean más convenientes en términos de rentabilidad para la empresa.

\section{CONCLUSIONES}

La empresa A.J. FERNANDEZ presenta muchas ventajas que pueden ser utilizadas a su favor para competir en el mercado a nivel internacional.

Desde el punto de vista económico, es indudable que el sector ofrece un gran potencial para dinamizar la economía de la región norte del país, especialmente para generar empleo para una población pobre, mayoritariamente mujeres con muy pocas alternativas de lograr salarios y condiciones de trabajo como las que ahora tienen.

Las perspectivas en el mercado internacional de puros son buenas debido al crecimiento de la demanda, especialmente entre nuevos segmentos sociales especialmente en EUA.

\section{BIBLIOGRAFÍA}

Asamblea Nacional. (22 de Noviembre de 1991). Ministerio de Fomento Industria y Fomento. Obtenido de Ministerio de Fomento Industria y Fomento: www.mific.gob.ni/LinkClick. aspx?fileticket...tabid=647...es-N

Asamblea Nacional. (25 de Abril de 2008). Dirección General de Aduana. Obtenido de Dirección General de Aduana: http://legislacion.asamblea.gob.ni/f/\% 28\$A11\%29/069E934BFC8DD587062574DE0069 C963?OpenDocument

Asamblea Nacional. (25 de Abril de 2008). Dirección General de Aduana. Obtenido de Dirección General de Aduana: http://legislacion.asamblea.gob.ni/b.l \%29/069E934BFC8DD587062574DE0069C963? OpenDocument

Ballesteros, A. (2001). Comercio exterior: teoría y práctica. Murcia: EDITUM.

Claver Cortés, E. (2000). Estrategias de internacionalización de la empresa. Madrid: Editorial Club Universitario.

Coventry, Pedro, Tomas Albert. (2000). Desarrollo de la comercialización Agrícola, 5ta. Edición.

De Ugarriza, S. (2009). Terminología comercial agropecuaria. Salta: Ediciones de la Universidad Catolica de Salta.

Gónzales López, I. (2014). Gestión del comercio exterior de la empresa $3^{\mathrm{a}}$ edición: Manual teórico y práctico. Madrid: ESICD587062574DE0069C963?OpenDocument 